\title{
Faith Assimilated to Perception: the Embodied Perspective
}

\author{
Elena Kalmykova ${ }^{1}$ (iD \\ Published online: 1 October 2020 \\ (C) The Author(s) 2020
}

\begin{abstract}
In this paper, I consider how the embodied approach can be applied to religious faith, and possibly other kinds of faith. I start with the reformed epistemologists' idea that religious faith is similar to sense perception, and I argue that we can elaborate this idea by taking into account our capability perceptually to grasp what is not accessible by senses - the 'presence in absence' (Noë 2012) or, as I call it, perceptual faith. As perception necessarily involves not only a mental but also an embodied relation to its object; an embodied relation can be seen as a constitutive component of faith as well. According to phenomenological accounts of perception (Merleau-Ponty, Noë, Siewert), embodiment and enactment allow humans to transcend perspectival limitations and to perceive an object as it is beyond its appearances: constant despite changes of angle, light, and other conditions and whole even when only parts of it are visible. I argue that, in the same vein, embodied relations and particular normativity involved in perception-based faith allow humans to transcend the precariousness of our experience and to sustain a perception-like relation to religious objects, achieved in a 'better look' moments of religious experience. I conclude that an embodied account can provide new insights into the nature of religious faith and resolve some puzzles, such as how faith can be a virtue.
\end{abstract}

Keywords Faith $\cdot$ Embodiment $\cdot$ Perception $\cdot$ Belief $\cdot$ Religious experience $\cdot$ Phenomenology $\cdot$ Epistemology

\section{Faith Based on Experience}

In this paper, I propose a novel model of religious faith, based on the embodied approach to perception. While some models of faith focus on the noetic structure of beliefs and the attitudes involved in faith that something is the case, according to a

Elena Kalmykova

Lyola.k@gmail.com

1 University of Uppsala, Uppsala, Sweden 
proposition (Tennant 1943; Schellenberg 2005; Swinburne 2005; Audi 2011; McKaughan 2013; Pojman 1986, 2001; Buchak 2012), others render faith as primarily an experiential or perception-like relation to God, or faith in (Alston 2005; Plantinga 2000, 1983; Hick 1966, 1968; Smith 1979). My account aims at the latter family of the models of faith, and in particular those assimilating it with perception. What interests me here is how new empirical data and phenomenology of perception can help us elucidate the possibility of perception-based faith in a transcendent God. Thus, I provide an account of perception-based experience and then base my model of faith on it. My contribution is quite modest: any novelty and usefulness of my account lies in explicating the role of body and action in faith. My account neither purports to exclude other views of faith nor rejects them and can be seen as complementary to those of John Hick, Alvin Plantinga, William Alston and other thinkers of this sort.

The paper proceeds as follows: to show how my model is related to existing ones, I start with a brief sketch of the most distinct accounts of faith that assimilate it to perception: Alston's non-sensory perception, Plantinga's sensus divinitatis and Hick's faith based on interpretation. I argue that these accounts are based on a mind-only concept of perception that leaves the role of body and action in faith undertheorised. Plantinga's account, to the extent it bases faith solely on the workings of a sui generis cognitive faculty of sensus divinitatis and depends upon the factual existence of this faculty, is problematic in light of the data from the cognitive science of religion (CSR). Next, I present important findings in phenomenology of perception and argue that empirical data do not in fact press us to introduce additional cognitive faculties in order to account for religious faith, but calls for introduction of body and action into it. Moreover, a proper attention to the human body and its role in perception opens up a possibility of modelling faith in God based on ordinary perception. Next, I identify normative and structural properties of perception that are relevant to accounting for religious faith. I start with the consideration of perception of 3D-objects, then move on to the objects of art, humans and, at last, the physical world and God. Finally, I argue that having experience and sustaining faith in God is based on the embodied and enactive properties of our perception. If my assumptions are correct, an embodied account proposes a possible important new perspective on faith.

\section{Faith Produced by a Special Cognitive Faculty}

Some of the most distinct accounts of perception-based faith were developed by the reformed epistemologists, such as William Alston (2005), Alvin Plantinga (1983) and others. As religious objects are non-sensory, the main task for perception-based models is to explain how one can have experiential access to a God not able to be sensed. The solution proposed by reformed epistemologists is to base religious faith on the work of representational doxastic mechanisms, similar to those involved in perception, but designed to fit religious objects. The mechanisms which they consider responsible for religious perception vary.

William Alston argues that humans obtain knowledge of God by means of mystical, non-sensory perception. He claims that religious objects can present themselves for our perception in a non-sensory experience. As religious objects, such as God, are purely spiritual, 'a non-sensory experience gives us a better chance of grasping what God is 
like in Himself than does any sensory experience' (Alston 1993, p. 20). Alston defines perception this way:

Perceiving $\mathrm{X}$ simply consists in $\mathrm{X}$ 's appearing to a subject $\mathrm{S}$, for example, or being presented to one, as so-and-so. That's all there is to it, as far as what perception is, in contrast to its causes and effects. Where $\mathrm{X}$ is an external physical object like a book, to perceive the book is just for the book to appear to one in a certain way. (Alston 2005, p. 442)

Thus, he argues that non-sensory experience of religious objects is similar to perception: God presents himself to us as God. Furthermore, non-sensory perception is reliable for the same reasons that other doxastic practices (that is, socially established ways of forming and epistemically evaluating beliefs) are deemed reliable.

While Alston defends non-sensory perception without much clarification regarding the nature of the faculty that makes this perception possible, Plantinga focuses his argument on a special faculty producing religious faith: sensus divinitatis. Plantinga considers religious belief as properly basic - that is, a belief that is not based on other propositions or beliefs. He compares the belief in God with the belief in other minds or belief in the past, which we are warranted to accept as true prima facie. He argues that beliefs based on our memory or perception are reliable as long as they are formed by normal functioning of innate cognitive mechanisms - for example, my belief that I had breakfast this morning is basic and reliable for me as long as my memory functions well. Similarly, faith is produced, according to Plantinga, by a normal functioning of sensus divinitatis that triggers religious belief in various circumstances, such as seeing the beauty of the world. Thus, faith in God follows from experiences of God, which we are prima facie justified in accepting, as long as they are delivered by a reliable faculty of sensus divinitatis.

Both Plantinga's and Alston's accounts are highly coherent and meticulously developed. Problems arise, however, when one attempts to find empirical correlates to the cognitive faculties and abilities which they postulate theoretically. Empirical study of religious cognition is undertaken by CSR, which studies the cognitive mechanisms that give rise to religious beliefs. However, these mechanisms do not have the properties of sensus divinitatis. Religious beliefs are produced as a side-effect of ordinary faculties of the human mind, such as an ability to attribute various events to the actions of an agent - agency detection device (ADD) (Barrett 2004). According to CSR, our ADD was evolutionarily developed to hyper-act, that is, to identify agency and intentions in almost everything that happens. For example, we tend to suspect a predator hiding behind a bush not only when there is enough evidence for that but upon hearing a slight rustling of the leaves nearby. Our hyperactive ADD encourages the generation and spread of god concepts (Barrett 2004, p. 31). However, for Plantinga interpretation of sensus divinitatis as a side-effect, similar to that of ADD, is not an option: he deems it to be a faculty whose main and proper function is to produce religious beliefs. Belief in God cannot be a side-effect that may or may not arise.

Empirical evidence from CSR in regard to the workings of an innate 'religious faculty' raises further problems for sensus divinitatis. Plantinga cites Calvin to show his reasons for postulating this faculty: 'This conviction, namely, that there is some God, is naturally inborn in all, and is fixed deep within, as it were in the very marrow' (Calvin 
1960, 43-44). Indeed, religious belief is ubiquitous, but the concept of God held by religious people is quite far from the theistic one. According to CSR, the faculties producing religious beliefs give rise to 'spiritual hunches' rather than theologically correct beliefs regarding a transcendent God. When not influenced by developed doctrinal religions, humans are naturally prone to develop beliefs about fairies, ghosts, spirits and other things that haunt bushes and cemeteries (Barrett and Clark 2010). This fact renders dubious the attribution of theistic belief solely to an innate faculty, and it also raises questions regarding the proper functioning of the God faculties, as even the simplest religious beliefs are highly diverse (animism, totemism, etc.). Thus, as David Basinger writes, 'lack of consensus in the religious realm makes it difficult to assume that religious faculties, in general, produce true beliefs' (Basinger 1991, p. 71). The same is applicable to Alston's argument for non-sensory perception: the experiences and beliefs it gives rise to are too diverse and controversial to trust it prima facie.

Thus, contemporary CSR fails to identify empirical correlates to the theoretically postulated faculties of Plantinga's model and renders problematic the attribution of theistic belief solely to the workings of an innate faculty. In the following, I will argue (quite boldly) that the problem here might be neither in CSR nor in the model per se, but in assumptions regarding perception, underlying Plantinga's model, that underestimate the role of body and informed action in perception.

\section{Faith in}

Unlike reformed epistemologists, John Hick intends to show that religious cognition is possible with a mundane set of human faculties. In his early writings $(1966,1968)$, Hick, just like W.C. Smith (1979), strives to ground religious beliefs in faith. Both Smith and Hick distinguish faith in as a special kind of faith: we have faith in God, and not merely that God exists. Smith grounds faith in a subjective, emotional state of personal allegiance and commitment, a relation to something beyond this world. Contrary to Smith, Hick focuses on the cognitive content of faith and claims that faith 'is more like sense perception than like propositional belief' (Hick 1968, p. 22). He argues that humans can have direct, non-sensory religious knowledge or experience of God by means of interpretation (which is always involved in perception). He points at the complexity and ambiguity of the world, where 'we never have before us unambiguously divine acts, but only ambiguous events which are capable of taking on religious significance to the eyes of faith' (Hick 1968, p. 26). In this sense, religious experience is on par with more mundane kinds of experience which involve interpretation.

In Hick's account, experiential awareness of God is reached in various kinds of religious experiences - from mystical and prophetic to those related to the aesthetic or moral appreciation of the world, bringing about a sense of the presence of God. Hick emphasised that a crucial requirement for having religious experience is a proper interpretation. Religious objects are not merely 'given' to a specific mental faculty, as in the accounts of reformed epistemologists, but reached by special efforts. One must act, to reach the real objects of religious belief. According to Hick, this action is proper interpretation. However, such interpretation is focused not primarily on individual instances of perception (seeing a beautiful sunset or having a vision of the Virgin Mary, for example) but on a global level. It is a religious interpretation of human life in general that is involved in faith, according to Hick. 
In sum, Hick puts the emphasis, in his account of faith, on perception-like recognition of a religious object (or, better to say, person). This recognition requires an act of religious interpretation of worldly events and situations in which God reveals himself. Putting together the ideas of Hick and Smith, we can suppose that to have faith in means to be in a perception-like relation to God. I find Hick's account especially illuminating, particularly due to his emphasis on the ambiguity of our perception and the role of action that is required for having religious experience and faith. However, I find it insufficient, as it does not delve into particularities of individual instances of perception. Nevertheless, I believe that we can expand his model, using empirical data and introducing body into it.

\section{Accounting for Religious Perception}

The accounts we have tackled use a certain idea of perception, and they assimilate faith to it, basing on its properties. We can distinguish some commonalities in the model of perception upon which Alston, Plantinga and Hick, despite the differences among their accounts, build. We can provisionally call it a mind-only model. According to it, in perception we are 'appeared to'. Our organs passively register sense data (or non-sensory data). They supply the data to our mind, which produces beliefs and judgements on the basis of them. Thus, heavy lifting in perception is done by the mind, while the role of the body is of no interest. Similarly, normativity is seen as pertaining to beliefs and judgements, which are formed on the basis of perception, but not to a process of perception itself.

This paradigmatic view of perception as what is happening in the mind is common in analytic philosophy. However, it was challenged recently by an approach, rooted in the continental tradition of phenomenology, that deems perception as embodied, situated and enactive (Noë 2004; Merleau-Ponty 1965). There is a rapidly developing framework, unifying research in cognitive science and philosophy of mind, which claims that body and actions are constitutive for perception and cannot be treated as merely causing it. As we have considered above, empirical data raise some problems for an attribution of theistic belief solely to a special cognitive faculty such as sensus divinitatis. However, I will argue that an embodied framework and proper attention to action and body in perception open up possibilities to incorporate empirical evidence into a perception-based account of faith. I deem that Hick's, Alston's and Plantinga's accounts do not preclude, and could benefit from, adding body to the picture. We might even say that Hick's account forestalls the enactive account of religious cognition - an idea that perception requires action. So, in the following, I will show that consideration of particularities of perception and embodiment gives rise to a novel model of faith, firmly grounded in phenomenology and empirical facts of human cognition.

\section{Embodied Faith}

\section{Embodied Framework}

Here I will consider perception in an embodied framework. The term 'embodied' is used to emphasise a constitutive role of body in cognition. Embodied models of 
perception claim that perception is what we do, that it is an action and that it cannot be accounted for by description of what is going in the mind only (Noë 2004; Merleau-Ponty 1965). To account for a visual experience of Mona Lisa, for example, one needs to refer not only to the mental representations or processing of sense data, but also to the positioning of the body, the movement of the eyes, etc. We do not merely acquire the sense data, but we strive to find the best angle, the optimal light, we step forward and backward and we might even visit the Louvre Museum at a time when there are fewer visitors, as noise and jostling easily disturb our perception of the painting. Thus, according to an embodied framework, body and actions are constitutive for perception, and we cannot properly account for perception without taking them into consideration. So, let us now consider the role of body and actions in perception from an embodied perspective.

\section{Perceiving More than Currently Accessible for Senses}

Before we move on to a consideration of perception, I want to emphasise one property that I believe is crucial for an embodied understanding of faith. Lack of clarity on this point leads to an entanglement of accounts of faith as propositional belief with accounts of perception-like faith. Here is the point: while propositional belief must be proportionate to available evidence, perception always transcends that which can be seen as 'available evidence'-that is, the data that are accessible for senses at a given moment. Normal perception is, in fact, a perception of what is not accessible by senses but is felt as present.

The simplest example of this can be found in vision. Due to the structure of our visual system, we are limited by respect of what we can see. As our retina is a surface, three-dimensional objects are projected to it as two-dimensional. Thus, we should only be able to see two-dimensional objects - something like flat pictures with patches of colour on them. Upon movement, we should see more flat pictures with changing patches of colour. Furthermore, because we occupy a specific position in space, we see everything from our egocentric perspective, as it appears to us from the particular point of view we currently have due to the positioning of our bodies in space. What is accessible at any given moment is only one side of objects, seen from a particular perspective: I see only one side of an apple under certain angle and light conditions. This is how Charles Siewert puts it:

All bodies' says Hume (1739, 1.2.5), “appear as if painted on a plane surface”. So all that visually appears to us is an array of two-dimensional colored shapes, as in a painting composed according to the rules of perspective: that is how experience is perspectivally constrained. But if this is right, bodies (being three dimensional) do not, rightly speaking, sensorily appear to us at all. Visual experience does not really reveal bodies for us to think about_-bodies are but a stable, bulky construction or conjecture of thought that organizes or explains fluctuations in the endless flatland of appearances. (Siewert 2015, p. 23)

Nevertheless, these limitations do not actually constrain our perception in a way we might expect them to. As Susanna Schellenberg (2010, p. 152) puts it, 'a subject's perception is not limited to the ways objects are presented in her egocentric frame of 
reference', and somehow the subject manages to transcend one's egocentric frame in action and in thinking. We perceive objects as independent of our perspective and stable in shape, despite the angle we choose to look at them and despite changes in light conditions. We perceive and think of objects as a whole, even though only a part or a side of the object is currently visible. For example, when we see a cat partly hidden behind a fence, we perceive it as a whole cat, and not as pieces of cat separated by the slats of the fence. We do not infer logically that the chance of there being a whole cat is higher than there being only pieces of a cat attached to a fence-we actually perceive a whole cat. A cat is present for us as a whole. Perception of what is hidden for us at the moment - such as a back side of the house-Merleau-Ponty describes as a positive presentation of something indeterminate, a presentation of I-do-not-know-what. One's experience of the back-side of an object is 'a vision of I do not know what' (Kelly 2005).

Thus, judging from what is actually accessible for our senses at any given moment, our perceptions of wholeness, depth or stability of objects cannot be seen as proportionate to available data. This transcendence of our limitations in perception can be put this way:

The content of perception: Accessible sense data do not supply us sufficient information to perceive whole and stable objects; therefore, the content of our perception exceeds sense data.

Alva Noë calls this phenomenological transcendence of perspectival limitations 'presence in absence' (2012, p. 18), claiming that perceptual experience extends to the hidden. But we can as well consider it as a sort of 'perceptual faith', because in it we reach out to something beyond appearances, to something that is transcendent to all appearances. We really 'see the invisible' at every given moment of our perception. This might be regarded as a sort of a puzzle: 'how can our visual experience, inevitably limited by perspective, provide us with something to think about and act upon, beyond that perspective?' (Siewert 2015, p. 23). How do we manage to perceive stable objects and not only changes of colour shapes on the two-dimensional surface of our retina? A possible answer to the puzzle is given by the embodied phenomenology. As Charles Siewert writes, what limits our perspective also opens possibilities for overcoming it. Our perception is designed to accommodate the fact that 'not all of what is apparent appears all at once' (Siewert 2015, p. 23). He claims that our experience, in fact, is constrained by perspective without being confined to it - and consequently, we are not its prisoners. We transcend perspectival limitation in various movements and perceptual actions towards the object.

...What, if anything, such experience is the appearance of, has features that do not vary with every change in appearance to you. And if what appears to you has features that do not vary when the appearance varies, then what appears is distinct from its appearing - it is, to that extent, something 'beyond' the experience. (Siewert 2015, 27)

Noë calls this capability a sensorimotor understanding - a skill that we master in our active engagement with the world. In action, we learn that upon slight movements of our head and body, we can have access to the hidden parts of the objects. In this sense, 
we are perceptually conscious of all the objects potentially accessible for our action- to varying degrees, however. The relation to a tomato in front of me is highly movement-dependent and changes even with the slightest movement; less so the relation to a hidden part of the tomato. Similarly, the relation to the Eiffel Tower is extremely weak in terms of being affected by my moves. Noë points out, moreover, that thanks to our capability skilfully to access the objects of perception even when they are hidden, we can relate to objects that are too far away to be seen-for example, to a friend currently visiting Berlin (Noë 2012, p. 26). In thinking about a friend, we relate to the same intentional object as in perception: 'When I think about Dominic in this way, he is present in my conscious thoughts, but he is present as absent. ... Dominic's presence-in-absence is different from that of the objects around me; but the difference is one of degree, not of kind' (Noë 2012, pp. 26-27).

Thus, our perception supplies us with something that is in fact beyond sense data. Thanks to perceptual faith, we are capable of directing our actions towards the object as a whole, spatiotemporal entity, and not only to that which is accessible to us in our limited perspective at any given moment. Our actions towards the object reveal progressively more properties of the object, which were present but indefinite (Kelly 2005), or present as absent (Noë 2012). Therefore, perceptual faith is crucial for guiding our action in the world, supplying us with the objects as they are to us as embodied beings, and not only to our retina.

If we compare perception with religious faith, we can find some similarity in respect to their content: faith in God transcends the appearances of the worldly objects accessible to senses and 'goes beyond' them. However, it is one thing to perceive invisible parts of a three-dimensional object; perceiving a transcendent God is a radically different thing. God, by definition, is beyond the world and inaccessible to our senses, not even in parts, as in the case of a cat hidden partly by a fence. Can we compare the mechanism of transcendence in perception and the mechanism of transcendence in religious faith? Further in this paper, I will consider this question and supply an example of perceiving transcendent God through the world, using Mark Wynn's idea of genius loci. For now, I want to draw the following conclusion from this discussion: embodied action in the world (and not merely interpretation) is crucial for perception of the objects that are not accessible to us due to our limitations.

But the question arises: if the content of our perception is provided by what we might call perceptual faith, is this faith justified? And how does this justification take place? So let us move on to the topic of normativity of perception.

\section{Better Look: Normativity in Perception}

\section{Perception of 3D Objects}

Sense experience has a peculiar structure making it different from judgements. When we perceive something, we are appeared to in a certain way; a thing looks somehow coloured and shaped - for example, it looks like a pink rat. But we do not always judge what colour or shape it has from how it looks or feels. We are constantly surrounded by myriads of shapes and colours, which we do not bother to judge by formulating expressions as 'this is pink'. However, when we formulate a judgement, it 'can linger in the absence of the sense experience that prompts them' (Siewert 2015, p. 18). 
A connection between perceptions and judgements seems quite straightforward. According to Plantinga, if I have a visual experience of a pink rat, or am appeared to pink-ratly, I have prima facie justification to believe I see a pink rat. Thus, sensory experience justifies our beliefs. A puzzle of perception, however, is that the same sense data that can give rise to different appearances. However, not all appearances present equally well the object of which they appear and lead to a correct judgement. For example, we can perceive an object both as it is independently of our perspective (the round rim of a cup as round), and as it looks within our perspective (the round rim of a cup as oblique). The sense data supporting our seeing of a rim as round are precisely the same as those supporting our seeing the rim as oblique. Now, it is not interpretation or judgement that distinguishes the former from the latter, because, as visual illusions show, an appearance often persists even after we renounce the judgement that it is the way it looks to us. For example, lines of the same length, even after we measure and judge them to be equal, still look different to us. Furthermore, we might mistakenly perceive something as a 3D-object. For example, we might suddenly realise that a house, towards which we are walking, is a well-executed painting on a flat surface, hiding a construction site. Thus, a question arises:

What is the difference in how it looks to you, in your visual experience of it, from which you first judge: bulgy, then-flat, if the appearance from which you judge is flat from beginning to end? The difficulty goes away, if we simply grant that the difference in experience was: it first looked to you bulgy, then flat. (Siewert 2015 , p. 25)

So the looks or appearances can be different - true to the object, or true to our limited perspective only. To account for this normative property of perception, Charles Siewert introduces a concept of better look. He writes that as we keep our perceptual relation to objects and approach them, we can reach 'a better look' at the object, which makes the 3D-object more apparent to us. This is how Siewert formulates this principle:

If I get a better look at something than I otherwise would have had, then often, to some extent, this increases the warrant or justification I have for making certain judgments about it. (Siewert 2015, p. 19)

So normativity of perception is based on an experience of better look. Siewert provides the following example to illustrate his point:

'Glove Quest'. I want to have my gloves to go out into the cold. I look for them in the chaos of my dresser drawer. In doing this, I look at various things in there, and finally get a good enough look at something to tell that's a glove. And when I do, I have warrant for judging it to be a glove. I then look for its mate, and by getting a good look at something else, I can tell-I am warranted in thinkingthis is the matching glove. (Siewert 2015, p. 19)

Similarly, what looked bulgy from my perspective at one point might look flat upon a better look - that is, often, upon looking closer and moving around the object. Thus, Siewert argues that our sense experience both has and confers a normative status. In 
getting a better look, the dynamic nature of our perceptual relation to the objects is at play. Due to the precariousness and limitations of our perception, there can be mistakes and illusions, showing our perceptual faith (the capacity of our perception to give us whole, stable objects beyond our limited perspective) to be misplaced. For example, our initial perception that the object is $3 \mathrm{D}$ might turn out to be wrong. But we identify our mistake not through rumination, but by perceptual action itself. Reaching a better look is not a matter of judgement added to the experience; rather it is achieved within the experience - this achievement can even strike us suddenly, as at the moment when we recognise that the house, to which we walked for the last $10 \mathrm{~min}$, is just a painting. Correct judgements are formed on the basis of better look experience and are warranted by it.

Thus, better look is what is happening within our perception. It allows us to overcome the precariousness and limitations of our perception, giving our perceptual experience meaning and value, and granting to us the object to think and act upon. As Siewert shows, our perception is designed to accommodate the temporal and spatial unfolding of perception. We perceive objects in series of actions upon them: moving around it, looking at it from different angles and under different light conditions, etc. Thus, our perceptual faith gets justified in our actions upon the object, by means of which we get to perceive more of the object. However, in getting a better look 'more is not always better' (Siewert 2015, p. 28). He gives an example of looking under the hood of a broken down car: if one does not have special knowledge of cars, one will not be able to perceive what is broken no matter how long one looks. Thus, what counts as a better look depends on the context, particular interests and abilities.

Siewert writes about cases where getting a better look satisfies the particular interest of a person, such as finding a glove or identifying the problem with a car. However, I believe we can expand to cases where we are not guided by a particular interest, such as 'glove quest'. Furthermore, we can get a better look as a matter of unbidden revelatory experience. Even though such experience stands out of our normal course of actions and perceptions, we still identify, within a perceptual experience, that we suddenly got a better look at something in comparison to our previous experience of the object.

\section{Perception of the Objects of Art}

From this simple example of a better look at a glove, we can make the next step and consider what comprises a better look at more complex objects, such as a work of art. As better look is relational, it is harder to establish the most revealing relation with complex objects. When it comes to such objects, better look requires special efforts on a part of humans, unless we are lucky to get the best perception just by chance or in revelatory experience. This is how Noë puts it:

You go to an art gallery and you look at a work of art in an unfamiliar style by an artist you don't know. It happens, sometimes, in a situation like this, that the work of art strikes you as flat or opaque. You don't get it. It is incomprehensible. But you don't give up. You look harder; maybe you recall another similar object that you've seen. You read the title of the piece and that gives you an idea. You overhear someone in the gallery make a comment about the piece-about how it was made. Something remarkable can now occur. The piece opens up to you; it 
discloses its face to you; you can see into it now and appreciate its structure. The piece now is present to you as meaningful... Whatever change has occurred, it enables you now to perceive, in the work, what you couldn't perceive before. (Noë 2012, p. 1)

This dependence of perception on not only action but also properly informed action requires more laborious and finely tuned better look the more the complexity of the object. We can consider, for example, a perception of an artwork like the Venus of Milo in a museum or an icon of the Saviour in a cathedral. We find the best position to get a better look at the Venus of Milo by moving around and trying different angles, but even that may be insufficient for a better look: if we visit the museum immersed in everyday troubles, tired and irritated after an hour in a museum-ticket queue, our perception of the Venus of Milo will hardly be as vivid and deep as when we are undistracted by negative bodily states and ready to dedicate all our attention and senses to this painting. If we read additional literature on this artwork, our look may be more informed and our attention may shift to details unnoticed before. This happened to Proust's hero Bergotte, after he learned that, in his favourite painting, Vermeer's Street in Delft, 'a picture which he adored and imagined that he knew by heart'; a critic of it remarked that 'a little patch of yellow wall (which he could not remember) was so well painted that it was, if one looked at it by itself, like some priceless specimen of Chinese art, of a beauty that was sufficient in itself' (Proust 1982, p. 185). When Bergotte came to the gallery to check that information, 'he remarked for the first time some small figures in blue, that the ground was pink, and finally the precious substance of the tiny patch of yellow wall' (Ibid.). The experience of vividness and beauty, revealed in this better look at the painting, was overwhelming: 'In a celestial balance there appeared to him, upon one of its scales, his own life, while the other contained the little patch of wall so beautifully painted in yellow. He felt that he had rashly surrendered the former for the latter' (Ibid.).

Thus, unlike propositional belief (for example, belief in God, triggered by sensus divinitatis), which is stable and singular, being stored properly in our belief system, perception is more like a fluid and ever-changing continuum. Both a brief, indifferent glance at a Venus of Milo statue and an immersed contemplation leading to a revelatory experience of this statue, (like the one experienced by a hero of Uspensky's story She Straightened Out (1979)), are, in fact, perceptions of the same object. Other ways of directing our senses to an object, everything which lies in this continuum, are also perceptions. However, in this continuum, we can identify a point of better look-a moment when we succeed in establishing a proper relation with the object, where the object is more apparent to us and becomes meaningful for us. This relation might be as simple as the recognition of a face in Octavio Ocampo's metamorphic painting or lead to a life-changing revelation, as it happened to Uspensky's hero, who felt that he was 'straightened' by the statue of Venus. In any case, a better look is not a property of the object itself or of the object and some external conditions. It is a relation that depends on the perceiving subject with his or her bodily and mental conditions, skills, interests, knowledge and context.

The precariousness of perception leads to a special value we attribute to experiences when we get a better look at things, because at those moments we establish the most revelatory relation to the object. Even though we might never get a similar revelatory 
perceptual experience of the Venus of Milo after we first achieved it, and our subsequent encounters with this work of art leave us dull and unmoved, we do not consider our revelatory experience unjustified or wrong. Our appreciation of an artwork or a person does not change together with the changes of appearances. Once moved by a better look at an artwork or a person, our relation to them remains the same (unless we deliberately abandon it, deciding that it was delusional). The statue of Venus makes Uspensky's hero come back to life in a transforming experience: he compares his soul with a creased glove that was straightened up. We can sustain our relation after it has been established in a better look experience-for example, Uspensky's hero keeps visiting the Louvre and decides to get a photo of the Venus of Milo to put on the wall in order to secure the continuous 'straightening' effect. Moreover, even if for a time we do not experience that artwork in the same way as in the better look moment, we keep on acting towards it on the basis of this continuing relation. It still possesses the meaning and value acquired in the better look moment.

\section{Faith in Humans and God}

Here I will consider how one can develop faith in, given the mechanisms and precariousness of perceptual experiences that we have considered above. Let us start with the consideration of faith in humans. Following the idea of perceptual faith, based on normativity of better look, I want to argue that we have faith in a person because we experienced this person as he or she is in the better look experience.

But what is a better look with respect to humans? As in the case of perception of simple 3D-objects, of which their parts that project in space may be temporarily inaccessible to our senses, persons protract in time, parts of their personality and their personal history are still in the future; the person may reveal his or her personality in particular deeds or misdeeds, but we cannot witness all of them. Nevertheless, we might say that a better look experience takes place when the person is the most apparent to us, as it may happen in a very sincere conversation, where we succeed in establishing a more revealing relation to the person. Thereafter, even though we might not perceive the actions of a person in certain circumstances (for example, I do not have perceptual access to my friend at all times), our faith is based on a once acquired better look experience of this person. Thus, I extend my relation to the friend, established in such an experience, beyond that particular instance. By extending it, I have faith in my friend. I do not need to check repeatedly whether she keeps my secrets, because her trustworthy personality extends into the future. This sort of faith is rational for the same reasons that our perception of $3 \mathrm{D}$-objects, transcending our perspectival limitations, is rational. We relate not only to the appearances we perceive right now, limited by our perspectival, time and space constraints. Instead, in our relation, we take into account that which was revealed to us, and sustain the relation to the whole person, as he or she exists in time. In this way, faith is 'the evidence of things not seen' (Hebrews 11:1) but is still warranted by our better look experience.

However, faith in is precarious: we can forget the beauty of another human being and how the person opened up for us. It is not a proposition regarding the person we might forget, but the very experience of the person achieved in an intimate relation to them that can fade. As a result, our relation will be to perspectively limit appearances, 
instead of to the person as a whole. So I argue that having faith in a person requires sustaining the relation to the person, once achieved in our better look perception of the person. This means that faith requires efforts to sustain this relation, as our everyday interaction with the person might not reveal the depth once opened to us.

\section{Faith in God}

Let us now move on to religious faith. As we have considered above, faith as a perception-like relation to an object can be regarded as justified in transcending the available evidence of appearances. As human beings, we are constrained by our limited perspective, not only upon simple objects like fences and cats but also upon the objects of art, other humans and the world. We are exposed only to appearances of them. Nevertheless, despite our perspectival constraints, just as in sense perception, we in faith in humans relate to objects as whole and stable, existing independently of our incomplete, temporal, perspectival and precarious access to them. Thus, by the same token, we can suppose that religious faith can be based on a perception-like relation to God, reached in a better look experience. Here I limit my consideration of faith to religious experiences of a mundane kind, that is, where God is perceived through interaction with a world, and not in a mystical vision, etc.

In the case of the religious objects of faith, one needs not only to transcend constraints of perspective, time and space but also to see beyond all the appearances of the entire world and everything that is in there, because God is transcendent. It is common for theologians to suggest that there is a certain relationship between God and the world that makes experiencing God through the world possible. For example, Thomas Aquinas deems that the world offers the best possible image of God:

God planned to create many distinct things, in order to share with them and reproduce in them his goodness. Because no one creature could do this, he produced many diverse creatures, so that what was lacking in one expression of his goodness could be made up by another; for the goodness which God has whole and together, creatures share in many different ways. And the whole universe shares and expresses that goodness better than any individual creature. (Aquinas 1997, 1.47.1)

Thus, the world shares something with transcendent God, and this property is expressed by the whole universe. But how can one experience God in this case? We can hypothesise that perception of what is beyond the appearances in the better look religious experience can be similar to Mark Wynn's conception of 'unified sense of place' (Wynn 2009, p. 47), where a place is the entire world. This is how he explains this conception:

The unity of a place such as Dartmoor (the English national park) resides in the fact that its parts all partake in a common character or spirit or 'atmosphere'.... The 'atmosphere' of the moor is not so much an agglomeration of individual features (architecture, climate, and so on) as a kind of alloy produced from the interpenetration of these various qualities in our experience of them. ... So when we speak of the unity of a place, and think of its parts as united by something 
other than their membership of a tightly circumscribed kind... the various parts of the place form a unity in so far as they all participate in a unitary 'atmosphere', which pervades the place as a whole. (Wynn 2009, p. 47)

Wynn calls this property of Dartmoor 'Dartmoorishness' and argues that it is 'a kind-transcending quality - it is exemplified not simply by trees, or rocks, or buildings, but by all of these things in so far as they participate in the character of the moor as a whole' (Wynn 2009, p.52). Hence, 'Dartmoorishness' is 'the manner of being that is exemplified by the moor as a whole and by individual things in so far as they form part of the moor' (Wynn 2009, p. 51). Thus, similarly to how we perceive stable and whole objects in a way that unifies the appearances and is beyond them, we perceive a property of places in a way that is not contained in any of its parts accessible to our senses but that unifies our perceptual experience of the place. Wynn applies the concept of the unity of a place with its particular atmosphere or genius loci to religious cognition. From his perspective, a supra-individual property of a place can be put in terms of genius loci. Dartmoorishness is the genius loci of Dartmoor, or the spirit of the place. Similarly, God is related to the world as the world's genius loci: 'the God-world relationship can be understood by analogy with the genius-place relationship' (Wynn 2009, p. 66).

Furthermore, in order to know a place, we need to be in that place - to spend some time to become familiar with various objects and properties in it. Moreover, just as it is the case with the objects of the arts, we need to make perception more informed by learning narratives and history of the place. Wynn argues that 'there is a kind of embodied knowing that is achieved in the practical appropriation of a place' (Wynn 2009 , p. 28). Certain 'content' is apprehended in 'embodied interaction with the places', while the most important thing is 'what one perceives, rather than what one does through enacted engagement with the place (through swooping or stooping, for example) - albeit that what one perceives is introduced by means of a gesture' (Wynn 2009 , p. 29). In a similar way, we can suppose that God can be experienced through our properly informed and attentive embodied encounters with the world and perceptions of it, even though God is not contained in the world and transcends it. Thus, in this account, experiencing God and obtaining faith in God are a matter of action, and not merely workings of an innate cognitive mechanism.

So we can suppose that one can perceive God as a particular genius loci upon better look experience through encounters with the world. This revelatory experience is not merely a matter of getting more encounters - as Siewert rightly notes, more is not always better in the case of perception $(2015, \mathrm{p}$. 28). The look at the world should be properly informed, just as our look at the artwork, of which Noë writes (2012). Often, better look religious experience of the world happens suddenly, as an unbidden appreciation of the world. An example of the religious experience of this kind can be found in the account of an American missionary, David Brainerd:

I was walking in a thick grove, unspeakable glory seemed to open to the apprehension of my soul. I do not mean any external brightness, nor any imagination of a body of light, but it was a new inward apprehension or view that I had of God, such as I never had before, nor anything which had the least resemblance to it. I had no particular apprehension of any one person in the 
Trinity, either the Father, the Son, or the Holy Ghost; but it appeared to be Divine glory. My soul rejoiced with joy unspeakable. [...] I continued in this state of inward joy, peace, and astonishment, till near dark without any sensible abatement; and then began to think and examine what I had seen; and felt sweetly composed in my mind all the evening following. I felt myself in a new world, and everything about me appeared with a different aspect from what it was wont to do. (Irvine 2015, p. 24)

As noted by Irvine, whose citation of Brainerd's account I use, though Brainerd speaks in terms of seeing God, the rest of his account indicates that he did not see anything, but instead he perceived the world anew. A similar account of seeing worldly appearances as altered can be found in Jonathan Edwards' report of his religious conversion:

The appearance of everything was altered; there seemed to be, as it were, a calm, sweet cast, or appearance of divine glory, in almost everything. God's excellency, his wisdom, his purity and love, seemed to appear in everything; in the sun, moon, and stars; in the clouds and blue sky; in the grass, flowers, and trees; in the water and all nature; which used greatly to fix my mind. (James 1902, pp. 248-9)

What is similar in these accounts is how this new meaning of the world - 'divine glory' - is experienced in the same mundane objects that before did not reveal this transcendent character. The entire world and everything in it are perceived, differently, as revealing the transcendent qualities-God's excellency, wisdom, purity and love. These qualities are not contained in the objects or in the world per se but are nevertheless experienced as present. They are present (or presented) in a way similar to Dartmoorishness in Wynn's experience of place, and to stability of objects in our everyday perception. Of course, such revelatory moments - those of better-look at the world - do not last long and are quite rare in the course of humans' everyday perceptions. Perception of divine glory or divine genius mundi in the world eventually fades. Thus, similarly to faith in persons, the relation to God, achieved in such experiences, can be sustained by embodied means.

\section{Sustaining Faith}

\section{Sustaining Faith in Humans}

Assimilating faith to embodied perception has important ramifications about what it means to have faith. If my assumptions are correct, we cannot consider faith to be sustained by itself: perceptual faith as a relation requires action to be sustained. It can be a matter of luck to get a revelatory better look at the world or at a person. However, to sustain it, we need to make certain efforts. Furthermore, just as we relate in perception to an object 'out there' by embodied action, and not in our mind (in interpretation or making judgements, for example), embodied action is required to keep this relation in faith. Otherwise, our relation would be not to the real object or person, but to something internal to our mind. 
So how can we sustain a once established relation when the object of that relation is not accessible for the senses? Humans are capable of sustaining a perception-based and perception-like relation even if the object is only 'present in absence' (Noë 2012). This is done by means of certain actions. Take, for example, the actions of a mother whose son has gone missing and is believed to be dead by others, but who keeps her faith that he is alive. (Here I want to specifically deny that her faith is propositional merely because it is expressed with a conjunction 'that'). Women in such situations report that they feel their children to be alive, as if they were present, only not here, and their faith is based on this perception-like feeling. This is how Nathan, a mother whose 18-year-old son went missing 10 years ago, puts it:

'I never allow myself to say he's dead,' Nathan says, visibly shaking that thought from her shoulders before continuing. 'I just have this vision of him walking into this room and he's there'. (Constable 2017)

A mother of a missing child directs her thoughts to her son 'out there', and not merely to a memory of him in her mind or a proposition. Her actions aim to keep her relation to her son, as a real person, temporarily inaccessible for her senses. 'She has had countless one-way conversations with her missing son since then, assuring him that he is loved and urging him to make contact' (Constable 2017). Moreover, she keeps his personal belongings untouched: 'She still has his yarmulke and a colorful ribbon from the Jewish youth group of which he was president. She keeps his clothes' (Constable 2017). It is common for the parents of missing children to preserve the child's room as it was left. These are particular embodied actions helping to sustain the perception-like relation to the real persons, temporarily inaccessible for a full-fledged perceptual experience.

Moreover, a mother can hardly sustain her faith without all these actions, which are part and parcel of faith. It would be rational, in view of a propositional belief that 'her son is alive', to remove her son's clothes: being 28 years old he would hardly wear the clothes he wore when he was 18 . It should be no problem to rearrange the home without a dedicated room for her son, as it is unknown when he will be back and he does not need such a room at the moment. Nevertheless, people like Nathan refuse to do that, insisting on keeping everything as it was when the child was present. I argue that a reason behind this is that these actions sustain their faith as a perception-like relation to their missing children. Propositional belief that 'my son is alive' does not require a mother to talk to someone not present, as the person cannot hear her. The same belief does not require one to direct thoughts and emotions to the person 'out there', as only a memory of this person is currently available. Even though following the other route is rational and compatible with a propositional belief that her son is alive, abstaining from actions that are part of faith breaks the perception-like relation of a mother to her missing son, leaving her only with a proposition instead of the felt link to her child. Thus, I argue that faith is sustained by a particular embodied demeanour and actions, aimed at keeping a perception-like relation to the persons and their parts or properties, not currently accessible for our senses. Moreover, these actions and the relation underlying them constitute faith. 


\section{Sustaining Faith in God}

If we now turn to religious faith, we find similar structures. As John Hick $(1966,1968)$ claims, faith presupposes particular perception-like experience. But as perception is precarious, religious experiences are quite rare. Thus, faith is what allows humans to sustain the perceptual relation to religious objects when they are not experienced as in the better look moment. The way it is done involves similar embodied structures and actions to those we find in sustaining faith in a missing child - directing thoughts and emotions to someone 'out there', revisiting the objects and places related to the one who is currently 'present in absence'. Religious experience does not take place in a void. It always happens in a certain place, or in connection to a certain object, in a certain social situation, etc. Thus, just as in perception of artworks, humans can strive to sustain a particular perceptual experience by visiting the same place, or perceiving similar objects, or communicating with people who managed to establish this perceptual relation - similarly to Wynn's account of knowledge of place (2009). So, in religious faith, we can find similar ways of keeping the relation that constitutes faith. Even though the objects related to in religious experiences are transcendent, the relation itself can be sustained by embodied and enactive means, by informed action in the world.

Thus, I argue that religious practice strives to provide the conditions for a perception-like experience of God. Practice is an enactment of faith, with a goal to keep or to restore the relation to the object once experienced but currently unavailable. Faith presupposes relating to the object—be that human or God-as it is, despite precariousness and perspectival limitations of our perception of it. To have faith means to relate to the whole object, transcending time and space, even if it is currently 'present in absence'. Our relation requires us to transform our lives and ways of action in order to make space for the person or object we want to stay related to, as it is done by Nathan in relation to her missing son. We keep that relation through our embodied action aspiring towards the object of faith. Further, as sustaining the relation and acting are deliberate and sometimes hard things to do, faith can be considered as a virtue. Thus, if we accept that faith is constituted by embodied actions that sustain the relation established in better look moments, it opens the way for regarding faith as a virtue and for preserving at the same time its cognitive component.

If my assumptions are correct, obtaining and sustaining perception-based faith might require more than the workings of an innate cognitive faculty. The account I have developed above implies that better look requires embodied and informed action on a part of a human, and a certain preparation - such as particular attentiveness to the world, a proper environment, etc. Introduction of embodiment and enactment into perception opens up the possibilities to respond to the critique of CSR and to the problems arising from attributing the content of faith to a special faculty, for example, why does this faculty produce different beliefs? Why does it not normally produce theistic beliefs? If what we perceive is not merely given, but depends on informed action and embodiment, then it is not likely that innate faculties per se, without properly informed action, will give rise to the uniform perceptions and beliefs across cultures and religions. Furthermore, normativity of better look presupposes that not experiencing God might be due to not making a good enough look, where appearances are perceived without seeing what is beyond then. We might suppose that organised 
religion provides skills and knowledge that allow humans to shape and sharpen the 'spiritual hunches' produced by innate religious faculties in a way similar to how studying art allows one to enhance and inform perception of beauty.

\section{Conclusion}

If we assimilate faith to perception and consider it in embodied framework, we can see how faith transcends human perspectival limitations. Perception-like faith can be seen as constituted and sustained by embodied actions, which are aimed at keeping the relation to the object beyond appearances, established in a better look experience. Faith allows humans to relate to the objects as a whole and protracted in time even though, due to our limited nature, we can only see the objects as a series of appearances. These limitations are caused by the human embodiment, but humans can use their embodiment and capability for informed action in order to transcend them. Of course, just as our perceptual faith might turn out to be unjustified and what we perceive illusory, our faith can turn out to be misplaced as well. But having faith, in fact, is truer to the way the world and people are, just as having perceptual faith and seeing objects as whole and three-dimensional is truer to the way the objects are, than what is given to us in a limited, egocentric perspective and in two-dimensional appearances. If it is true that faith is similar to perception, then it is a justified means to transcend the limitations of human, egocentric frames of reference.

Funding Open access funding provided by Uppsala University. This project has received funding from the European Union's Horizon 2020 research and innovation programme under the Marie Sklodowska-Curie grant agreement No 660954- BBP.

Open Access This article is licensed under a Creative Commons Attribution 4.0 International License, which permits use, sharing, adaptation, distribution and reproduction in any medium or format, as long as you give appropriate credit to the original author(s) and the source, provide a link to the Creative Commons licence, and indicate if changes were made. The images or other third party material in this article are included in the article's Creative Commons licence, unless indicated otherwise in a credit line to the material. If material is not included in the article's Creative Commons licence and your intended use is not permitted by statutory regulation or exceeds the permitted use, you will need to obtain permission directly from the copyright holder. To view a copy of this licence, visit http://creativecommons.org/licenses/by/4.0/.

\section{References}

Alston, W. (1993). Perceiving God: the epistemology of religious experience. Ithaca: Cornell University Press. Alston, W. (2005). Religious experience as perception of God. In S. M. Cahn (Ed.), Ten essential texts in the philosophy of religion (pp. 440-449). New York: Oxford University Press.

Aquinas, T. (1997). Summa Theologiae. In T. McDermott (Ed.), Summa Theologiae: a concise translation. (tr. William Wallace). London: Methuen.

Audi, R. (2011). Rationality and religious commitment. Oxford: Oxford University Press.

Barrett, J. (2004). Why would anyone believe in God? Walnut Creek: Altamira.

Barrett, J., \& Clark, K. (2010). Reformed epistemology and the cognitive science of religion. Journal of the American Academy of Religion, 79(3), 500-513.

Basinger, D. (1991). Plantinga, pluralism, and justified religious belief. Faith and Philosophy, 8(1), 67-80. 
Buchak, L. (2012). Can it be rational to have faith? In J. Chandler \& V. S. Harrison (Eds.), Probability in the philosophy of religion (pp. 225-246). Oxford: Oxford University Press.

Calvin, J. (1960). Institutes of the Christian religion, tr. Ford Lewis battles. Philadelphia: Westminster Press book 1 .

Constable, B. (2017). After 10 years, Buffalo Grove mom believes she'll find her son. In Daily Herald. Retrieved from http:/www.dailyherald.com/news/20171017/constable-after-10-years-buffalo-grovemom-believes-shell-find-her-son on 10.02.2018.

Hick, J. (1966). Faith and knowledge (2nd ed.). Ithaca: Cornell University Press.

Hick, J. (1968). Religious faith as experiencing-as. In Royal Institute of Philosophy Lectures, 2, 20-35.

Irvine, W. B. (2015). Aha!: The moments of insight that shape our world. New York: Oxford University Press.

James, W. (1902). The varieties of religious experience: A study in human nature. London: Longmans, Green, and Co..

Kelly, S. (2005). Seeing things in Merleau-Ponty. In T. Carman (Ed.), The Cambridge companion to MerleauPonty (pp. 74-110). Cambridge: Cambridge University Press.

McKaughan, D. (2013). Authentic faith and acknowledged risk: dissolving the problem of faith and reason. Religious Studies, 49(1), 101-124.

Merleau-Ponty, M. (1965). Phenomenology of perception. Trans: Colin Smith. London: Routledge \& Kegan Paul.

Noë, A. (2004). Action in perception. Cambridge: MIT Press.

Noë, A. (2012). Varieties of presence. Cambridge: Harvard University Press.

Plantinga, A. (1983). Reason and belief in God. In A. Plantinga \& N. Wolterstorff (Eds.), Faith and rationality: Reason and belief in God (pp. 16-93). Notre Dame: University of Notre Dame Press.

Plantinga, A. (2000). Warranted Christian belief. New York: Oxford University Press.

Pojman, L. (1986). Faith without belief. Faith and Philosophy, 3, 157-176.

Pojman, L. (2001). Philosophy of religion. New York: McGraw-Hill.

Proust, M. (1982). Remembrance of things past. In The Captive, The Fugitive \& Time Regained. (Translated by C. K. Scott Moncrieff) (Vol. 3). New York: Random House.

Schellenberg, J. (2005). Prolegomena to a philosophy of religion. Ithaca: Cornell University Press.

Schellenberg, S. (2010). Perceptual experience and the capacity to act. In N. Gangopadhyay, M. Madary, \& F. Spicer (Eds.), Perception, action, and consciousness: Sensorimotor dynamics and two visual systems (pp. 145-159). Oxford: Oxford University Press.

Siewert, Ch. (2015). On getting a good look: Normativity and visual experience. In M. Doyon, Th. Breyer (Eds) Normativity in perception (pp. 17-38).

Smith, W. C. (1979). Faith and belief. Princeton: Princeton University Press.

Swinburne, R. (2005). Faith and reason (2nd ed.). Oxford: Oxford University Press.

Tennant, F. R. (1943). The nature of belief. London: Centenary Press.

Uspensky, G. (1979). [1885] 'Vypriamila (Otryvok iz zapisok Tiapushkina)' in Rasskazy (pp. 341-364). Moscow: Khudozhestvennaia literatura.

Wynn, M. (2009). Faith and place: An essay in embodied religious epistemology. Oxford: Oxford University Press.

Publisher's Note Springer Nature remains neutral with regard to jurisdictional claims in published maps and institutional affiliations. 